\title{
Some metabolic, diversity and toxicity aspects of bacterial communities life in aquatic sediments
}

\begin{abstract}
Sediment is a special realm in aquatic environments and has high microbial diversity. Addition of organic electron donors to sediments stimulated heterotrophic activity. Bacteria utilize the more available fractions of the organic detritus in their own metabolism, leaving indigestible residues known as marine humus. Input of nitrogen and carbon from vegetated regions into freshwater sediments also stimulate aerobic, anaerobic and chemolithotrophic sediment microbes. Because bacteria respond dramatically to changes in their chemical environment, can be predicted rapid responses by the aquatic sediment microbial community to any change in plant species that affects sediment porewater chemistry. Temperature and rainfall can affect the some microorganisms growth and permanence such as E. coli and Enterococcus spp. The increase of pollutants load (e.g. $\mathrm{Pb}$ and $\mathrm{Zn}$ ) in water can be expected with the reduction of flow, whereby the decrease of pathogens concentration can be due to high concentrations of metals (e.g. $\mathrm{Hg}$ and $\mathrm{Pb}$ ) discharges in rivers. The enrichment of metals and nutrients concentration in sediments, especially in those with the fine texture, highlights that the adsorption process is the prevailing selfpurification mechanism. Investigations of short-term variations of microbiological and chemical parameters in the water column have implied that, despite seasonal and daily variations, microbial standing stock biomass and activity in one and the same body of water do not change drastically from one day to the other. Marine sediments contain as much as 18 per cent organic matter and bacteria in bottom deposits may grow and multiply. Enteric bacteria may be concentrated in bottom sediments of rivers as a result of sedimentation of bacteria-bound particles. Although it has been demonstrated that microbial communities can affect chemical pollutants, the presence of toxicants can also affect microbial community structure.
\end{abstract}

Keywords: Sediment; Bacteria; Water; Environment; Communities
Volume 5 Issue 4 - 2017

\section{Slobodan Zlatkovic}

Technical Commission of Ministry of Agriculture and Environmental Protection for evaluation impact assessment studies of activities and projects on the water environment, Serbia

Correspondence: Slobodan Zlatkovic, Technical Commission of Ministry of Agriculture and Environmental Protection for evaluation impact assessment studies of activities and projects on the water environment, Serbia, Omladinskih brigada I, I I070 Belgrade, Serbia, Email Slobodan.zlatkovic.bk@gmail.com

Received: June 15, 2017 | Published: July 31, 2017
Abbreviations: T-RFLP, Terminal restriction fragment length polymorphism; POM, particular organic matter; DOM, dissolved organic matter; ALAN, artificial light at night; PCR, polymerase chain reaction; PLFA, phospholipid fatty acid; DTPA, diethylenetriamine pentaacetic acid+tea buffered to $\mathrm{pH} 7.3$

\section{Introduction}

Bacterial communities have a great importance in aquatic sediments and water. They are main degraders of organic and some inorganic compounds. Bacteria participate in cycling of nitrogen through nitrification and denitrification, as in cycling of some other elements. Microbial biomass may be significantly in relation to rate of $\mathrm{C}$ source consumption in all lake sediments, suggesting that microbial activity is limited by C availability. Findlay (2003) showed that the addition of different carbon sources, i.e., glucose, bovine serum albumin and natural leaf leachate to hyporheic biofilms enhanced microbial activities. ${ }^{1}$ Carbon sources may influence nitrate reducing activity of the biofilm. Methanol is the most widely used carbon source for denitrification in reactors. Higher denitrification rates have been obtained with acetate as a carbon source. Also, abundance of denitrifying bacteria in the biofilm may be influenced by different carbon sources. This can be monitored by investigating the density of nosZ gene which codes for the nitrous oxide reductase, the last step of denitrification. The structural parameters of the biofilm formed under different carbon sources were examined and it was observed that the acetate and ethanol biofilms were mosaic-structured with the characteristic voids, whereas confluent biofilms were formed with glucose and methanol. The community structure of the biofilm established under different carbon sources were analysed by the DGGE fingerprinting method. According to the analysis, a $27 \%$ change in community occurred when the carbon source was changed from acetate to glucose, but $71.5 \%$ community change was observed from glucose to methanol transition. ${ }^{2}$

Since gradients in microbial function may correspond to chemical gradients, microbial biodiversity may also respond to changes in sediment chemistry that are linked to above-sediment plants. Freshwater sediments may protect allochthonous bacteria (Escherichia colli, Enterococcus faecalis, Vibrio cholerae, V. parahaemolyticus, $V$. salmonicida, Pseudomonas fliorescens, Styphylococcus epidermidis) from variety of stressors and enteric bacteria are often found at higher concentrations in sediment than in overlying water column. The diversity and composition of bacterial communities have been shown to be affected by metal contamination of their habitat. Therefore, toxic metals can be classified as a stressor that according to ecological theory should cause a shift in community composition toward lower diversity and metal tolerant bacterial strains. Bacterial tolerance to heavy metals is commonly coded by genes located on extra chromosomal elements (plasmids).

\section{Discussion}

\section{Metabolic patterns}

Addition of organic electron donors to sediments stimulated heterotrophic activity. Wang et al. ${ }^{3}$ showed that addition of electron donors (glucose, sucrose and potato starch and sodium acetate) stimulated denitrification in Lake Taihu (China) sediments. In the 
study of benthic microbial response to the deposition of natural seston in Lake Erken (Sweden), Törnblon and Rydin (1998) showed that seston addition caused an immediate increase in bacterial production, activity and total sediment metabolism. Generally, sediments responded rapidly to addition of most electron donors by increasing $\mathrm{CO}_{2}$ production rates. Sediments from site $\mathrm{KR}$ in Lake Okeechobee with the lowest microbial biomass exhibited the longest lag phase before responding to electron donor addition. Microbial biomass was significantly related to rate of $\mathrm{C}$ source consumption in all lake sediments, suggesting that microbial activity is limited by $\mathrm{C}$ availability. Although the magnitude of response to electron donor additions was related to microbial biomass, varied responses in sediments were probably related to catabolic diversity of microorganisms utilizing these substrates. Results of Principal Component Analysis 1 showed that Lake Apopka (Central Florida) sediments had the highest respiration per unit of microbial biomass with most of the electron donor additions (propionate, lake-SS, butyrate, acetate, and formate), indicating that these sediments respired most of the added $\mathrm{C}$. These sediments support high rates of microbial activity, as indicated by rapid utilization of a wide range of electron donors. There were found that, after seston addition to sediment, bacterial biomass doubled indicating assimilation of $\mathrm{C}$ into microbial biomass. King and Klug (1982) reported that the addition of glucose into microbial biomass was low $(20 \%)$ in a eutrophic lake sediment (Wintergreen Lake). Basal $\mathrm{CH} 4$ production rates were highest in sediments of hypereutrophic Lake Apopka. Low rates of basal $\mathrm{CH} 4$ production found in eutrophic Lake Okeechobee sediments may be explained by electron donor limitation, or by the presence of iron oxides which potentially can inhibit methanogenesis. Methanogens have the ability to use only a limited number of substrates, including $\mathrm{H}_{2}, \mathrm{CO}_{2}$, formate, acetate, methanol and methylated amines. The lag phase observed for $\mathrm{CH} 4$ production in all sediments can be explained by two mechanisms: (1) Methanogenic activity stimulated in the presence of substrates produced by fermentative activity, and (2) Methanogens becoming active after other electron acceptors (Fe(III), SO42-) were consumed and depleted in sediment microcosms. Methanogens have the ability to use only a limited number of substrates, including $\mathrm{H}_{2}, \mathrm{CO}_{2}$, formate, acetate, methanol, and methylated amines. The most important substrates for methanogens are $\mathrm{H}_{2} / \mathrm{CO}_{2}$ and acetate, and they often depend on other anaerobic bacteria for these substrates. Most methanogenic species use $\mathrm{H}_{2} /$ $\mathrm{CO}_{2}$ and a fewer number of species can use acetate. Circumneutral to alkaline sediment $\mathrm{pH}$ creating good conditions for hydrogenotrophic methanogenesis. Other studies have shown that $\mathrm{CH} 4$ production at low temperature $(4 \mathrm{oC})$ in sediments was mainly from acetate, however, an increase in temperature $(20-25 \mathrm{oC})$ lead to an increase in contribution of $\mathrm{CH} 4$ production from $\mathrm{H}_{2} / \mathrm{CO}_{2}$. Slightly higher temperature at the sediment-water surface $(26.3-30.7 \mathrm{oC})$ creates good conditions for hydrogenotrophic methanogenesis. Study has shown that sediments with different biogeochemical properties have microbial communities that exhibit distinct catabolic responses to a range of $\mathrm{C}$-sources. The hypereutrophic lake with higher $\mathrm{C}$ availability in its sediments had the highest catabolic diversity, where the microbial communities were able to efficiently use a broader range of substrates.

The oligo-mesotrophic lake sediment microorganisms had lowest efficiency in use of energy. ${ }^{1}$ The lack of water circulation in stratified water bodies (with a thermocline and halocline) in conjunction with continuous $\mathrm{O} 2$-consumption by remineralization leads eventually to complete $\mathrm{O} 2$ depletion. First nitrate and then sulphate is used for the degradation of organic materials in anoxic water. As a result, H2S is then produced by dissimilatory reduction of sulphate by sulphate- reducing bacteria. ${ }^{4}$ Bacteria change indigestible forms such as chitin or celluloses into more digestible bacterial protoplasm. Bacteria may serve as food for metazoa, and it is known that they are an important food for protozoa. The bacteria, however, also utilize the more available fractions of the organic detritus in their own metabolism, leaving indigestible residues known as marine humus. ${ }^{5}$

Input of nitrogen and carbon from vegetated regions into freshwater sediments stimulate aerobic, anaerobic and chemolithotrophic sediment microbes. Since gradients in microbial function may correspond to chemical gradients, microbial biodiversity may also respond to changes in sediment chemistry that are linked to abovesediment plants. Bacteria are abundant both in water (more than $10^{6} \%$ $\mathrm{ml}$ ) and in aquatic sediments (more than $10^{9} / \mathrm{gdw}$ ), although not all bacteria are metabolically active at any one time. Specifically, aerobic metabolism, denitrification, metal reduction, sulfate reduction and methanogenesis all appear to vary over these spatial scales. These results suggest that a diverse assemblage of bacterial functional groups coexists in freshwater sediments. Work by Dahm has shown that the availability of specific forms of electron donors and electron acceptors in ground water affects microbial composition and dynamics in freshwater sediments. Under the appropriate conditions, one or more microbial functional groups may become active and dominant. Thus, functional diversity, and perhaps species diversity of freshwater sediment microbes must be very dynamic over time and space, and may respond rapidly to changes in water chemistry induced by changes in the overlying plant species composition. ${ }^{5}$

Temperature and rainfall can affect the microorganism's growth and permanence such as E. coli and Enterococcus spp. The enrichment of metals and nutrients concentration in sediments, especially in those with the fine texture, highlights that the adsorption process is the prevailing self-purification mechanism. As well as the sediments represent a memory of aquatic ecosystem, their role of sink of pollutants and nutrients is correlated to fine size (silt and clay) and iron and manganese oxides. The Clostridium spores in sediments indicate a fecal contamination and their growth depends on the $\mathrm{S}$ and $\mathrm{C}$ content because they are sulphur-reductive bacteria involving in the sulphur-compound demolition in anoxic environment. The high concentration of metals in sediments can compromise the life of the aquatic ecosystem, but the pollution risk from metals depends on their chemical speciation rather their total elemental contents. The extraction with EDTA and DTPA solutions reveals a different percentage of availability of the metals in sediments and the high amount extracted by EDTA is due to the acid $\mathrm{pH}$, while the DTPA with neutral $\mathrm{pH}$ does not extract the metals immobilized in sediments. High percentage of $\mathrm{Pb}$ and $\mathrm{Cu}$ are extracted by both solutions highlighting a greater pollution risk than the other metals which are poorly extractable. Adsorption of pollutants in sediments seems be the main self-purification mechanism while the low pathogenic contamination is related to severe drought during the spring-summer period that, lowering the river flow, will increase the concentration of pollutants in water. Sediment is the sink of nutrients and pollutants and their hazard can be evaluated by metals speciation and by their availability. ${ }^{6}$

The profundal sediment of deep lakes is characterized by constant temperature throughout the year. Addition of algae to the profundal sediment of a freshwater lake resulted in a systematic sequential change in both activity and composition of the active microbial community, which eventually led to methanogenic decomposition of the added algal organic matter. Increased metabolic activity in summer thus can be caused only by change in chemistry, for example, input of fresh organic matter by sedimentation of algal biomass. The 
change in chemistry is reflect, for example, in simulated sedimentation of Peridinium gatunense cells onto intact sediment cores, resulting in an enhanced $\mathrm{CH} 4$ production rate and in the formation of products of organic matter fermentation (propionate, acetate), especially within the upper sediment layers. Bacterial populations are involved in decomposition of the added algal biomass. Addition of algal biomass to the sediment core resulted in increased concentrations of acetate and in doubling of the $\mathrm{CH} 4$ production rate from within the upper sediment layers. Dissolved organic matters is probably converted by the concerted activity of fermenting bacteria, syntrophic $\mathrm{H} 2$-producing bacteria and methanogenic archaea, resulting in increase of acetate, propionate, $\mathrm{H}_{2}, \mathrm{CO}_{2}$ and $\mathrm{CH} 4$ concentrations immediately after addition of algal biomass. The quantity as well as quality of available organic material caused changes in the structure of the bacterial community. Analysis of the microbial community by fluorescence in situ hybridization and denaturing gradient gel electrophoreses showed that addition of algal biomass resulted in a fast and selective increase of distinct bacterial groups. In marine sediments, respiratory processes, sulfate reduction in particular, dominate the decomposition of organic matter. Here has been analyzed reverse-transcribed $16 \mathrm{~S}$ rRNA on addition of algal biomass to sediment sampled. Although the data cannot be directly compared because of different sampling times and targeting rRNA versus rDNA, they are consistent with respect to the main features of the archaeal and bacterial communities. In particular, always observed a relatively high abundance of members of the Deltaproteobacteria and Bacteroidetes phylum, but also of Chloroflexi, Planctomycetes, mmaproteobacteria and Epsilonproteobacteria. After $1 \mathrm{~d}$ of incubation, T-RFs allocated to Desulfobacterales, trophobacterales, and Myxococcales dominated the bacterial T-RFLP(terminal restriction fragment length polymorphism) profile of the algal amended slurries. Since sulfate was not detectable after $1 \mathrm{~d}$ of incubation, the high relative abundance of Desulfobacterales must be due to metabolism other than sulfate reduction. The detection of Syntrophobacterales is reasonable since members of this order, such as Syntrophobacter wolinii (X70906), may have contributed to the syntrophic degradation of propionate that transiently accumulated on addition of algae. After 6 $\mathrm{d}$ of incubation, the structure of the active bacterial population changed again with members of the Bacteroidetes phylum (formerly known as Cytophaga-Flavobacteria-Bacteroides group) becoming dominant. The Bacteroidetes phylum has already been described as one of the most abundant bacterial groups in aquatic habitats including freshwater lakes sediments. Therefore can be assumed that Bacteroidetes-related bacteria were involved in the degradation of $P$. gatunense thecae which consist mainly of polysaccharides. Bacteroidetes related bacteria (designated as "Cytophaga") became abundant in algal-amended marine sediments. Although the next relatives of the clone sequences retrieved gave no clue to a particular phenotype, it can be assumed that populations of Bacteroidetes-related bacteria were primarily involved in the degradation of POM (particular organic matter) and became abundant as soon as the more labile DOM (dissolved organic matter) had been consumed by Clostridiales and Deltaproteobacteria. This study has shown that the addition of algae to the profundal sediment of a freshwater lake resulted in a systematic sequential change in both activity and composition of the active microbial community, which eventually led to methanogenic decomposition of the added algal organic matter.

Between dissolved and particulate organic matter, mutual exchange processes can be expected as indicated by the inverse variation pattern of glucose and organic matter content of the sediments. Variations in the total number of microbial cells correspond to organic nutrients and microbial activity. However, the higher the number of cells, the lower the concentration and the turnover time of glucose. From the calculations of microbial uptake activity, it is understandable that variations of both actual uptake rate and turnover time of glucose correspond to variations of glucose and total monosaccharides. The physicochemical parameters obviously influence microbial activity indirectly by various relationships existing between salinity, temperature, or both and parameters of dissolved organic carbon, which in turn relate to microbial activity. Saprophytes do not correlate well with total number and biomass. The only pronounced relationship exists between saprophytes and respiration rate of glucose. Pigmented saprophytes (percentage of the total number of saprophytes) show interrelationships with the concentration of glucose and total monosaccharides and actual uptake rates of glucose. Investigations of short-term variations of microbiological and chemical parameters in the water column have implied that, despite seasonal and daily variations, microbial standing stock biomass and activity in one and the same body of water do not change drastically from one day to the other. $^{8}$

Artificial illumination near surface freshwaters has the potential to be a viable night-time energy source for microbial phototrophs, some of which can carry out photosynthesis at light levels that are near to those generated by artificial light at night (ALAN). ${ }^{9}$ Artificial light can most certainly be used for photosythesis, as a photon from the sun may be no different from one emitted by a light bulb, they may only be different in intensity or colour. However, the rate at which photosythesis occurs is dependent on the spectral emissions of the light source.$^{10}$ Phototrophic organisms are able to carry out photosynthesis at low artificial light levels (e.g. after five months of illumination). This could result in changes to the microbial community as conditions may favor taxa that benefit from nocturnal (low-level) light. These changes could, in turn, influence ecosystem-level processes such as carbon turnover. In general, community respiration and net ecosystem production incorporates biochemical pathways that make organic carbon molecules and energy available to microorganisms and exhibit a strongly positive relationship with temperature. Such changes may also vary temporally because day length and light levels (along with temperature) act as seasonal cues for many organisms in natural systems. There have been carried out field and laboratory experiments to examine changes to microbial community structure and carbon mineralization in sediments of an agricultural drainage system. Such a long-term approach, including multiple generations of most microbes, potentially provides an important insight into temporal change in community structure and associated process rates arising from light. In the current study has been observed increased abundance in some phototrophic taxa in sediments after five months of illumination. Phototrophs again showed an increase in response to ALAN, but this was much more pronounced in the pre-exposed site. After 1 year of artificial illumination in the lit site, this trend continued with the pretreated sediment no longer showing a clear seasonal response to temperature. Results from the pre-treated sediment community suggest that ALAN may be the sole trigger and that it may override other seasonal triggers such as temperature. Consequently, this results in a loss of temporal structure and may lead to a loss of diversity.

\section{Diversity of bacterial communities in various types of sediments}

Illumina tags may be used for the study of bacterial diversity. Wang et al.11 determined millions of Illumina reads for a comparison of bacterial communities in freshwater, intertidal wetland and marine sediments along Pearl River, China, using 
a technically consistent approach. Statistical analysis (LEfSe) demonstrated that the freshwater sediment was enriched with Acido bacteria, Nitrospiraz, Verrucomicrobia, Alphaproteo bacteria and Betaproteo bacteria. The biomass and taxon richness of microbes in sediment are much higher than those of the corresponding water bodies. They determined sediments along the Pearl River in south China and performed a detailed comparison of the bacterial diversity and indicator bacterial groups in each type of sediment. Even though there has been used the Illumina instrument with stringent quality controls to determine the tag sequences, there are still many biases introduced by PCR error, sequencing error, sequencing depth and the bioinformatics pipeline. As the most diverse and even community, the freshwater sediment had the highest number of indicator taxa distributed in a variety of lineages, of which Acidobacteria, Nitrospira, and Verrucomicrobia were the three major indicators. Although the Acidobacteria phylum accumulated in the freshwater sediment, not all subdivisions of the phylum were the same. Result and recent reports suggest that subdivision 6 (Gp6), Gp1, Gp3, Gp4, and Gp18 (from high to low confidence) are enriched in the freshwater environment while subdivisions Gp10, Gp22, Gp21, and Gp26 are more abundant in marine sediments. In addition to Acidobacteria, Nitrospira is another strong indicator. Proteobacteria was the most abundant and largest phylum in all three sediments, but its classes showed different tendencies. Within the phylum, Alphaproteobacteria and Betaproteobacteria were enriched in the freshwater sediment, Gammaproteobacteria in marine sediment, Epsilonproteobacteria in intertidal wetland, and Deltaproteo bacteria in all sediments. In comparison, the bacterial groups enriched in marine sediment were mainly limited to the Gammaproteo bacteria and Deltaproteo bacteria, and almost all of them were involved in sulfur reduction. A large number of photoautotrophic microbes, e.g., Chloroflexi, Bacillari ophyta and Ectothiorhodo spiraceae (from the order of Chromatiales) were significantly enriched in intertidal environments. In addition, many chemolitho autotrophic bacteria from Epsilonproteo bacteria were also enriched in intertidal sediment, such as Sulfurovum and Arcobacter (Campylo bacterales). All of these results suggest that the intertidal sediment is highly productive and has various types of primary producers which contribute to the high nutrient concentration in the intertidal environment. Microbial communities from three different habitats showed obvious differences, which could not be fully explained by the limited factors determined in the present study. The freshwater sediment had the highest diversity, with Acido bacteria, Nitrospira, Verrucomicrobia, Alphaproteo bacteria and Betaproteo bacteria as indicators. The intertidal sediment had medium diversity, with many primary producers (such as Chloroflexi, Bacillariophyta, Gammaproteo bacteria, and Epsilonproteo bacteria) and eutrophic microbes (such as Bacteroidetes, Firmicutes, and Actinomycetales). The marine sediments had the lowest diversity and was enriched with Gammaproteo bacteria and some Deltaproteo bacteria orders, which were mainly involved with sulfate reduction under anaerobic conditions. ${ }^{11}$

Molongoski et al. ${ }^{12}$ examined anaerobic heterotrophic bacteria from freshwater Wintergreen Lake sediment. The most striking feature of the bacterial strains isolated from Wintergreen Lake sediments is the predominance of clostridia among the organisms examined. The genus Clostridium accounts for $71.8 \%$ of the total isolates. Greater than $50 \%$ of the clostridial strains, in turn, were identified as $C$. bifermentens and $C$. sporogenes (47.7 and $17.8 \%$, respectively). Although toxicity tests were not performed, C. sporogenes was nevertheless identifiable due to its characteristic "medusa-head" colonial morphology. A saccharolytic isolate tentatively identified as $C$. butyricum represented a minor portion of the clostridial isolates $(6.3 \%)$. The largely proteolytic nature of the clostridial isolates obtained is likely due to the predominance of nitrogenous organic substrates in Wintergreen Lake sediments. Matches and Liston (1974) examined the sediments of Puget Sound for the presence of clostridia. They reported anaerobic plate counts ranging from $0.73 \times 104$ to $23.5 \times 104$ cells $/ \mathrm{ml}$ of sediment-water slurry. Approximately $30 \%$ of these organisms were determined to be clostridia, the three species isolated in greatest numbers being $C$. perfringens, $C$. bifermentens and $C$. novyi. Finne and Matches (1974) have recently reported the isolation of low-temperature growing clostridia from marine sediments that can grow at $5 \mathrm{oC}$ or less, well within the in situ temperatures of most marine and freshwater sediments. The production of characteristic clostridial fermentation end products from [U-14C] glucose and a U-14C-labeled amino acid mixture by natural sediment microbial communities provides additional presumptive evidence that clostridia, and possibly C. bifermentens and C. sporogenes in particular, are active in the degradation of organic substrates in Wintergreen Lake sediments. C. bifermentens and C. sporogenes elaborate an array of characteristic volatile metabolites, including the distinctive valeric and caproic series of fatty acids. With the exception of a few species of anaerobic cocci (Peptostreptococcus sp.) and a small number of Bacteroides sp. and Eubacterium sp., the production of valeric and isovaleric acids as fermentative end products is generally limited to the genus Clostridium. These results support the hypothesis that a resident clostridial community is actively metabolizing in Wintergreen Lake sediments, particularly during periods in the summer and early fall when sediment temperatures are most favorable for growth of the clostridia. The diverse modes of anaerobic energy-generating metabolism displayed by members of this genus, their demonstrated ability to grow at environmental temperatures and their ability to form dormant spores whenever environmental conditions become unsuitable for growth should afford the clostridia a definite advantage in organically enriched anoxic habitats such as lake sediments. ${ }^{12}$

In addition to living organisms, clear sea water contains 0.2 to $2.0 \mathrm{ppm}$ of both inorganic and organic particles in suspension. Since approximately half of this particulate material is inorganic and claylike it may be expected that bacteria will be adsorbed and that the particles will eventually settle and be deposited on the ocean floor. Attached organisms thus become removed from surface waters and accumulate in sediments. Marine sediments contain as much as 18 per cent organic matter and bacteria in bottom deposits may grow and multiply. Russell (1892) demonstrated that there were greater numbers of bacteria in marine sediments than in overlying waters, and Rubentschik reported that coliform bacteria were absorbed by muds from salt lakes. More recently, it was confirmed that TraA, the major filament protein of the F-pilus, is essential for the development of highly organized, mature E. coli K-12 biofilms. The presence of TraA pili could support biofilm maturation even in the absence of flagella, type 1 fimbriae or $\mathrm{Ag} 43$, thus providing further confirmation that the latter are surface appendages that promote the initial adsorption of the cells to the solid surface, but are dispensable for later stages of biofilm development. Conjugative pili can accelerate initial adsorption depending on the nature of the abiotic surface and growth conditions but they are also specifically involved in biofilm maturation. ${ }^{13}$ The adsorption capacity of muds varied and there were differences in the susceptibility of different bacteria to adsorption. Similar results were obtained by Waksman and Vartiovaara (1938) who demonstrated that the clay fraction of marine sediments adsorbed more bacteria than did silt or sand. Weiss (1951) reported that sea water flocculated and 
decreased the capacity of silt to adsorb bacteria. ${ }^{14}$ Clay accumulation is so important to the total sediment specific surface area and accumulation of clays in intertidal sediments evidently requires biological incorporation. ${ }^{15}$ Diénert and Guillerd (1940) and Nusbaum and Garver (1955) attributed reduced bacterial counts to adsorption and sedimentation of coliform bacteria in sea water. Large numbers of coliform bacteria were detected in marine sediments underlying the paths of two outfalls that discharged unchlorinated sewage (Rittenberg et al. 1958), and it appeared that sedimentation was responsible for the distribution observed..$^{14}$ Enteric bacteria may be concentrated in bottom sediments of rivers as a result of sedimentation of bacteriabound particles. Auer and Niehaus (1993) showed than greater than $90 \%$ of fecal coliform in lake water was associated with smallsized particles in the range of $0,45-5 \mu \mathrm{m}$. Such particle associations influence the sedimentation rate of bacteria generally by increasing the rate of loss compared to unattached cells. Freshwater sediments may protect allochthonous bacteria form variety of stressors and enteric bacteria are often found at higher concentrations in sediment than in overlying water column. Sediment-bound enteric bacteria may become re-suspended by variety of perturbations including dredging, storm events and ship traffic. For example, Grimes (1980) reported an increase in indicator bacteria densities of 4-50 times in waters below dredging operations as compared to upstream waters. ${ }^{16}$

\section{Responses and adaptations of bacterial communities on toxic agents}

Although it has been demonstrated that microbial communities can affect chemical pollutants, the presence of toxicants can also affect microbial community structure. Chemicals can alter the community structure through selection of pollutant degraders or through acute toxicity to microorganisms. Readily biodegradable pollutants can increase population densities by promoting growth through providing carbon and energy to microorganisms in otherwise oligotrophic environments. The greater the oil contamination the more numerous were the hydrocarbon-degrading bacteria. Chronic exposure to petroleum hydrocarbons have been proposed as a partial explanation for variability in bacterial response to these chemicals. Perhaps of even more importance are the factors, such as type of bacteria present at the site, the physical and chemical characteristics of the oil, oil surface area, predation by protozoans or scouring of attached biomass by wave activity, ${ }^{17}$ that determine the carrying capacity for oil degrading bacteria in a marine beach environment. The physical environment of the bacterial assemblage seems to play a major role in the biodegradation capacities. ${ }^{18}$ Study in the Antarctic has shown that sea-ice bacteria actively grow and assimilate dissolved organic substrates. The presence of sea ice did not inhibit the development of total and specific bacterial communities in underlying seawater. Bacteria in sea ice have been reported to be generally larger than those found in seawater, which may be are reflection of generally higher organic nutrient concentrations in the ice environment, lower temperature or lower grazing pressure. In any case, addition of fertilizer strongly enhanced this phenomenon. All results revealed a clear response of Antarctic microbial communities to hydrocarbon contamination. Two orders of magnitude increases of total bacterial abundance were observed after crude oil contamination with added fertilizer. The biodegradation of hazardous substances is often limited by the antimicrobial action of the pollutants. Such inhibiting effects against bacterial communities seem relatively uncommon. They appear to be very weak and occur only in the early stages of experiments. It is well established that nutrients are one of the major limiting factors of hydrocarbon biodegradation at sea. In this survey the bacterial growth was doubtless improved by the availability of mineral nutrients released by hydrocarbon. As noted, some increases in bacterial numbers after hydrocarbon addition may be attributed to the bacteria growing on the oleic acid contained by the fertilizer. The considerable enrichment in hydrocarbon-degrading bacteria after a few days of crude oil contamination is a clear indication of possible biodegradation. This is consistent with chemical analysis of residual hydrocarbons, which demonstrated a decrease of the aliphatic fraction. Nevertheless, under similar conditions of very low temperature, the rates of biodegradation observed during this study were relatively slight. It is reasonable to assume that the limiting factor was the temperature characteristics of the enzymes that carry out the initial oxidative steps. However, biodegradation indicators were weak but perceptible. ${ }^{19}$

Dutka and Kwan (1982) compared the results off different methods of detecting toxicity to bacteria and found that each method had its own sensitivity pattern to toxicants. The relative toxicities of the compounds compared very well whether the acetate incorporation or the glucosidase activity method was used. With the acetate incorporation method, toxic compounds were inhibitory to microbial communities taken from above a sewage treatment plant outfall than to those taken from below. There are two possible explanations for this. Much organic material is added to the stream with the treatment plant effluent, and this could cause chelation of the toxicants. Also, the organisms below the plant could be more resistant to perturbation due to selection since they are more continuously exposed to more toxic compounds than are those from above. This could be especially true of the sediment community since it is less mobile than the water column community. ${ }^{20}$ Bacterial communities react in various ways in response to toxic factors. Frostegård et al. ${ }^{21}$ studied the effect of heavy metal pollution on the microbial community in the soil by performing a phospholipid fatty acid (PLFA) analysis. They found that addition of $\mathrm{Cd}, \mathrm{Pb}, \mathrm{Zn}$ and $\mathrm{Ni}$ induced similar changes in the PLFA pattern, while the effect of $\mathrm{Cu}$ addition on the PLFA pattern differed from the effects of the other metals. Positive correlations between metal contents and the percentages of bacteria tolerant to heavy metals have also been observed with sediments and in aquatic environments. The opposite result was observed by Dean-Ross and Mills (1989) in a study of the responses of planktonic, sediment and epilithic bacterial communities to heavy metal pollution. However, these authors suggested that the lack of correlation between metal concentration and resistance in the sediment bacterial community was due in part to the high $\mathrm{pH}$ of the river water, which reduced the toxic effect of the heavy metals present. In polluted soils, particularly soils contaminated with $\mathrm{Cu}, \mathrm{Zn}$, and $\mathrm{Cd}$, the appearance of colonies was delayed compared with unpolluted soil. The data support the conclusions of Doelman and Haanstra (1986, 1989), however, who found that the slopes of the doseresponse curves for $\mathrm{Cd}, \mathrm{Cr}, \mathrm{Cu}, \mathrm{Ni}$ and $\mathrm{Zn}$ for urease and phosphatase activities obtained in soils polluted with these metals differed from the slopes obtained in unpolluted soils. To overcome this problem, Doelman and Haanstra suggested the use of an ecological dose range (defined as the dose range in which activity decreases from 90 to $10 \%$ of the undisturbed activity) instead of the IC50 values used in ecotoxicological studies. IC50 and IC10 values were closely related ( $\mathrm{r}$ $=0.909, \mathrm{P}<0.001)$. The levels of tolerance of the bacterial community to the different metals in soils polluted with low doses were in some cases even lower than the levels of tolerance in the unpolluted control. These results and those reported by Frostegård et al. ${ }^{21}$ seem to support this assumption since (i) an increase in the tolerance of the bacterial community and changes in the PLFA pattern were found at similar metal concentrations and (ii) similar effects of heavy metal additions were deduced after the bacterial communities were grouped on the 
basis of the results of a PLFA pattern analysis and tolerance pattern measurements. ${ }^{21}$

Nayar et al. ${ }^{22}$ studied reactions of heterotrophic bacteria on heavy metals in mangrove sediment environment in Ponggol Estuary. This study revealed very high concentrations of heavy metals in suspended particulates and sediments compared to the levels in water. It is a mangrove ecosystem and the fact that mangrove mud binds metals explains the elevated heavy metal levels in particulates and sediments. Also, fine sediments have a larger surface area, which allows heavy metals and other contaminants to be adsorbed easily. In the aquatic and sediment environment, bacteria have been reported to have a wide range of metal detoxification or resistant mechanisms. Bacteria immobilize metals and nullify their toxicity by sequestering the metals to their extracellular polymer matrix, excluding or by precipitating the metals into an insoluble mineral matrix. The toxic effects of metals have been stated to be attenuated by the precipitation and complexing capacities of the bacteria. Other detoxification mechanisms in bacteria include the formation of an extracellular polysaccharide capsule that acts as a metal trap, the presence of metal-resistant membrane proteins, and plasmid encoded metal efflux. In the presence of sulphate or phosphate, bacterial assemblages have been reported to detoxify cadmium by forming insoluble cadmium-phosphate or cadmium-sulphide complexes, which are precipitated out of solution. Observations along similar lines were made of an increased incidence of zinc-tolerant bacteria, linking the zinc tolerance to multiple-metal resistance. These observations provide evidence that heterotrophic bacteria can adapt well when exposed to high heavy metal concentrations and make use of the dissolved organic carbon pool available from the disintegration of the less-tolerant organisms. This explains the enhanced rates of heterotrophic bacterial production and increased total bacterial biomass in treatments with high concentrations of metals. It was apparent that bacterial heterotrophs were not affected by the background concentrations of heavy metals that were biologically available from the sediments re-suspended by dredging. ${ }^{22}$

Studies of the effect of sludge application on the microbial flora have focused on the discharge of pathogenic organisms into the environment and the changes in microbial mediated nutrient cycling. Even those studies that examined the response of the endogenous microbial community to accumulated heavy metals have assessed soil enzyme activities, rather than microbial community structure. The diversity and composition of bacterial communities have been shown to be affected by metal contamination of their habitat. Numerous reports are available which correlate the extent of metal pollution with bacterial resistance in soil, water and sediment. Therefore, toxic metals can be classified as a stressor that according to ecological theory should cause a shift in community composition toward lower diversity and metal tolerant bacterial strains. Bacterial tolerance to heavy metals is commonly coded by genes located on extra chromosomal elements (plasmids). Among natural bacterial communities the development of resistance to stressors could be greatly enhanced by the horizontal spread of resistance plasmids. Elucidation of the relationship that exists between bacterial plasmid patterns and the response of the community to pollutants may contribute toward a better understanding of the role of plasmids in adaptation to environmental stressors. ${ }^{23}$

\section{Conclusion}

Bacterial communities in aquatic sediments have some specific properties since they live with lack of light, in low temperature and with variable amount of oxygen. But, their metabolic role remains the same as in above water because significant part in element cycling belongs to them. Bacteria may degrade almost all organic compounds during the time, including some inorganic, creating important conditions for life in their habitat. Various factors affecting their diversity and shifts during the circadian and season period.

\section{Acknowledgements}

None.

\section{Conflicts of interest}

The authors declare that there is no conflict of interest.

\section{References}

1. Torres IC, Inglett KS, Reddy KR. Heterotrophic microbial activity in lake sediments: effects of organic electron donors. Biogeochemistry. 2010;104(1-3):165-181.

2. Srinandan CS, D'souza G, Srivastava N, et al. Carbon sources influence the nitrate removal activity, community structure and biofilm architecture. Bioresour Technol. 2012;117:292-299.

3. Wang Y, Liu J, Zhao H, et al. Human 1A6/DRIM, the homolog of yeast Utp20, functions in the 18S rRNA processing. Biochim Biophys Acta. 2007;1773(6):863-888.

4. Gast V, Gocke K. Vertical distribution of number, biomass and size-class spectrum of bacteria in relation to oxic/anoxic conditions in the Central Baltic. Marine Ecology Progress Series. 1988;45(1/2):179-186.

5. Mare MF. A study of a marine benthic community with special reference to the micro-organisms. Journal of the Marine Biological Association. 1942;XXV:517-554.

6. Palmer MA, Covich AP, Lake S, et al. Linkages between Aquatic Sediment Biota and Life Above Sediments as Potential Drivers of Biodiversity and Ecological Processes. BioScience. 2000;50(12):10621075 .

7. Ferronato C, Modesto M, Stefanini I, et al. Chemical and Microbiological Parameters in Fresh Water and Sediments to Evaluate the Pollution Risk in the Reno River Watershed (North Italy). Journal of Water Research and Protection. 2013;5(4):458-468.

8. Schwarz JIK, Eckert W, Conrad R. Response of the methanogenic microbial community of a profundal lake sediment (Lake Kinneret, Israel) to algal deposition. Limnology \& Oceanography. 2008;53(1):113121.

9. Meyer-Reil LA, Bolter M, Dawson R, et al. Interrelationships Between Microbiological and Chemical Parameters of Sandy Beach Sediments, a Summer Aspect. Appl Environ Microbiol. 1980;39(4):797-802.

10. Hölker F, Wurzbacher C, Weißenborn C, et al. Microbial diversity and community respiration in freshwater sediments influenced by artificial light at night. Philos Trans $R$ Soc Lond B Biol Sci. 2016;370(1667):20140130.

11. Wang Y, Sheng HF, et. al. Comparison of the Levels of Bacterial Diversity in Freshwater, Intertidal Wetland, and Marine Sediments by Using Millions of Illumina Tags. Appl Environ Microbiol. 2012;78(23):82648271.

12. Molongoski JJ, Klug JJ. Characterization of Anaerobic Heterotrophic Bacteria Isolated from Freshwater Lake Sediments. Appl Environ Microbiol. 1976;31(1):83-90.

13. Houdt RV, Michiels CW. Role of bacterial cell surface structures in Escherichia coli biofilm formation. Research in Microbiology. 2005; 156(5-6):626-633.

14. Carlucci AF, Pramer D. Factors Affecting the Survival of Bacteria in Sea Water. Microbiological Process Report. 1959;7(6):388-392. 
15. DeFlaun DF, Mayer LM. Relationships between bacteria and grain surfaces in intertidal sediments. Limnology \& Oceanography.1983;28(5):873-881.

16. Pettibone GW, Irvine KN, Monahan KM. Impact of a ship passage on bacteria levels and suspended sediment characteristics in the Buffalo River. Water Research. 1996;30(10):2517-2521.

17. Anonymous. Fact Sheet: Bioremediation in Oil Spill Response. NRT Science and Technology Committee. 2000:1-3.

18. Delille D, Delille B. Field observations on the variability of crude oil impact on indigenous hydrocarbon-degrading bacteria from subAntarctic intertidal sediments. Mar Environ Res. 2000;49(5): 403-417.

19. Delille D, Bassères A, Dessommes A. Effectiveness of bioremediation for oil-polluted Antarctic seawater. Polar Biology. 1998;19(4):237-241.
20. Barnhart CLH, Vestal R. Effects of Environmental Toxicants on Metabolic Activity of Natural Microbial Communities. Appl Environ Microbiol. 1983;46(5):970-977.

21. Díaz-Ravińa M, Bååth E, Frostegård A. Multiple Heavy Metal Tolerance of Soil Bacterial Communities and Its Measurement by a Thymidine Incorporation Technique. Appl Environ Microbiol. 1994;60(7):22382247.

22. Nayar S, Goh BPL, Chou LM. Environmental impact of heavy metals from dredged and resuspended sediments on phytoplankton and bacteria assessed in in-situ mesocosmos. Ecotoxicol Environ Saf. 2004;59(3):349-369.

23. Barkay T, Tripp SC, Olson BH. Effect of Metal-Rich Sewage Sludge Application on the Bacterial Communities of Grasslands. Appl Environ Microbiol. 1985;49(2):333-337. 